\title{
Fractional Order Sliding Mode Control of PMSG-Wind Turbine Exploiting Clean Energy Resource
}

\author{
Muhammad Waseem Khan*, Jie Wang*, Linyun Xiong and Meiling Ma
}

Department of Electrical Engineering, Shanghai Jiao Tong University, Minhang, Shanghai, 200240, PR China

\begin{abstract}
The extensive application of permanent magnet synchronous generator (PMSG) based wind energy conversion system (WECS) has attracted growing interests of power researchers on its control and operation. This paper aims to propose a kind of fractional order sliding mode based (FOSM) power output control scheme of PMSG based WECS with fast exponential reaching law (FERL). The FERL based FOSM control technique proves to be better capable of attenuating the level of the chattering phenomenon with faster convergence speed. The boost converter and the neutral point clamped inverter, both of which are utilized to connect the PMSG and the power grid, are controlled with the proposed FOSM control scheme. Furthermore, the direct and quadrature grid current are tracked, which leads to the control of the active and reactive power output. The effectiveness of the proposed method is verified with an $8 \mathrm{~kW}$ wind turbine simulation and the test results indicate that the proposed method can better track the reference value of active and reactive power. In addition to that, the total harmonic distortion level of the grid current is largely mitigated.
\end{abstract}

C2019.CBIORE-IJRED. All rights reserved Keywords: Renewable energy, Boost converter, Fast exponential reaching law, FOSM, Neutral point clamped inverter, PMSG, Wind turbine.

Article History: Received June $2^{\text {nd }}$ 2018; Received in revised form October $6^{\text {th }}$ 2018; Accepted January $7^{\text {th }} 2019$; Available online

How to Cite This Article: Khan, M.W., Wang, J., Xiong, L. and Ma, M. (2019). Fractional Order Sliding Mode Control of PMSG-Wind Turbine Exploiting Clean Energy Resource. International Journal of Renewable Energy Development, 8(1), 81-89.

https://doi.org/10.14710/ijred.8.1.81-89

\section{Introduction}

In present years, owed to the double pressures of environment and electrical power, the complications around surroundings and applications of clean energy covered the attention of modern researchers. Hence, renewable energy resources have been measured as a best substitute energy source, because non-renewable energy resources like, fossil fuels are inadequate and create huge environmental pollution problems. Integration of renewable energy resources, such as; wind/solar energy with power system can be affectively improve the scarcity of clean energy, eliminate producing of harm gases due to diesel generators/coal, and will also lead to generate electricity with comparably low prices (Nguyen et al., 2013; Khan et al., 2018; Nascimento et al., 2017). With the expansion of higher capacity of wind energy, improved power compactness, advanced system consistency requirements and unfortunate low voltage drive through competence of the fractional order converters, several different forms of generation arrangements have been established newly. Due to its compensations, a direct driven permanent magnet synchronous generator (PMSG) has acknowledged higher attention in the current time. Power density of PMSGs have usually higher, having low preservation prices, as a consequence of no slip rings and gearbox, and complete gauge control converters with greater grid competency (Hui et al., 2016; Zhou et al., 2015).

Greatest studies in the area of PMSG-based wind energy conversion system (WECS) are devoted to the growth of suitable governor practices to rise its capability to stream and adjust active as well as reactive power in mutually grid associated and grid islanding approaches (Delfino et al., 2012; Santiprapan et al., 2017). Numerous governor tactics have been practiced for PMSG-based WEC regulator to decrease current of generator, to retain dc-link voltage persistent, to abstract more electrical energy from wind turbines, to up-keep reactive power implanted to the network, and to minimize harmonics of current at point of common coupling (PCC). Such control approaches of PMSG-wind turbines can be normally organized into dual classes (Zhong et al., 2015). In the initial class, maximum power point tracking (MPPT) is accomplished by converter at machine-side control (MSC), while the dc-link voltage is controlled by converter at grid-side control (GSC) (Li et al., 2012; Muyeen et al., 2013). In the next class, GSC regulates the dynamic power abstraction from wind turbine, and the dc-link voltage governor is attained by MSC control (Yuan et al., 2009).

\footnotetext{
* Corresponding author: engr_waseem90@yahoo.com, jiewangxh@sjtu.edu.cn
} 
In the direct driven PMSG wind energy organization, PMSG is directly fixed to the wind turbines. By consuming a full back-to-back converter system, PMSG stator is associated to the utility grid. Field oriented or vector controllers, and direct control arrangements of power are the foremost supervisors for grid and machine side converters. For MSC, stator current of PMSG is measured in field oriented/synchronous locus mountbased vector control consuming outmoded PI-controllers (Zhou et al., 2015; Fatu et al., 2014; Pradhan et al., 2017; Melício et al., 2010). However, the traditional PIcontrollers has slowed and poor operations specifically during momentary actions and do not reflect the discrete process of the converters. Hence, due to powerful and rapid micro-processors, the operation of progressive control practices is possible. Such as, sliding mode control (SMC), neural networks, fuzzy logic control, and model predictive control can be functional for power converters in modern research.

SMC is the furthermost attractive non-linear controller, because of its effectiveness, robustness, quick dynamic response and high regularity swapping switch control approach for non-linear arrangements with reservations. Sliding mode controller has been used for pitch angle and torque of PMSG, renewable energy scheme is measured deprived of the supposition that wind swiftness is assessable (Mozayan et al., 2016; Yin et al., 2015; Lee et al., 2011). High directive sliding mode control system is planned to control the chattering spectacles of the primary directive sliding mode controller. Nevertheless, the accomplishment stage, and chattering spectacles constancy issues are currently the core difficulties of primary-order SMC.

This paper aims to propose a kind of fractional order sliding mode based (FOSM) power output control scheme of PMSG based WECS with fast exponential reaching law (FERL). The FERL based FOSM control technique proves to be better capable of attenuating the level of the chattering phenomenon with faster convergence speed. The general organization of the article includes: In Section 2, modelling and control system of PMSG-WECS is presented. In Section 3, fractional order sliding mode control (FOSMC) is discussed in details along with the designing and stability analysis of the system. Section 4, provides, simulation results and discussion along with the performance evaluation of the proposed controller and Section 5 concludes the paper.

\section{Modeling and control system of PMSG-WECS}

\subsection{Dynamic model of PMSG}

The general topology of a grid-connected PMSG based WECS is shown in (Fig. 1). In the PMSG based WECS, the PMSG machine is connected to the boost converter with a diode rectifier. The boost converter can be modelled as follows:

$$
\begin{aligned}
& \frac{d I_{d c}}{d t}=-\frac{R_{d c}}{L_{d c}} I_{d c}+\frac{1}{L_{d c}} V_{r}-\frac{(1-q)}{L_{d c}} V_{d c} \\
& \frac{d V_{r}}{d t}=\frac{1}{C_{0}} I_{r}-\frac{I_{d c}}{C_{0}}
\end{aligned}
$$

where $R_{d c}$ and $L_{d c}$ represent the resistance and inductance, respectively; $I_{d c}$ denotes the inductor current; $\mathrm{V}_{\mathrm{r}}$ and $\mathrm{I}_{\mathrm{r}}$ represent the rectifier output voltage and current, respectively; $V_{\mathrm{dc}}$ denotes the dc-link voltage which serves as the state variable and can be controlled by the grid currents; $\mathrm{C}_{0}$ represents the capacitor; $0 \leq \mathrm{q} \leq 1$ represents the duty cycle which can be used to generate the switching signal.

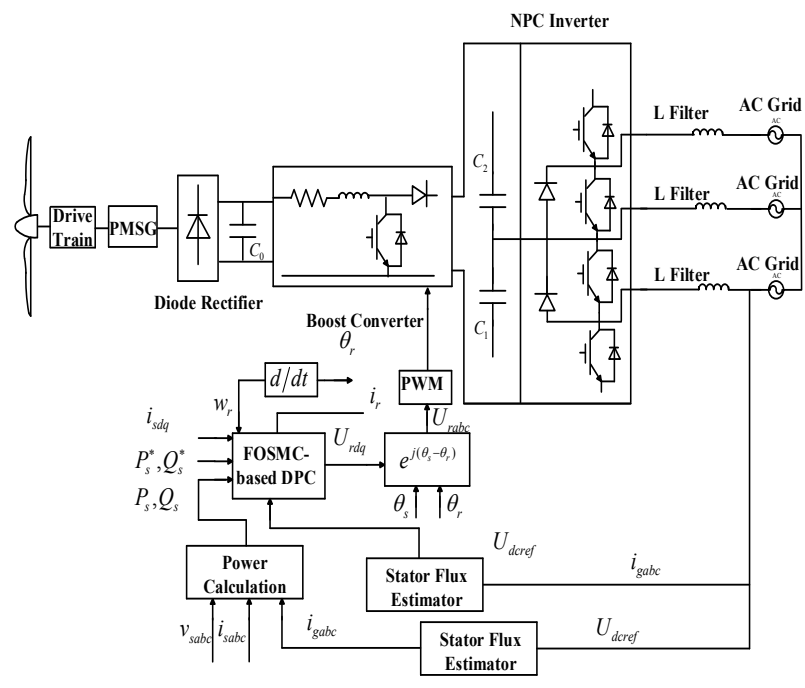

Fig. 1 Grid-connected PMSG based WECS

The wind energy is captured by the turbine blades and transferred to the PMSG with a drive train. Following that, the PMSG transfers the mechanical energy to the $\mathrm{AC}$ power grid via the diode rectifier, boost converter and the neutral point clamped (NPC) converter. For the L filter, the following equations hold;

$$
\begin{aligned}
& \frac{d i_{d g}}{d t}=-\frac{R_{f}}{L_{f}} i_{d g}+\frac{1}{L_{f}} v_{d i}-\frac{1}{L_{f}} v_{d g}+w_{g} i_{q g} \\
& \frac{d i_{q g}}{d t}=-\frac{R_{f}}{L_{f}} i_{q g}+\frac{1}{L_{f}} v_{q i}-\frac{1}{L_{f}} v_{q g}-w_{g} i_{d g}
\end{aligned}
$$

Where $R_{f}$ and $L_{f}$ represent the filter resistance and inductance, respectively; $v_{\text {di }}$ and $v_{\text {qi }}$ represent the output voltages of the NPC inverter; $v_{\mathrm{dg}}$ and $v_{\mathrm{qg}}$ denote the grid voltage in the $d$-axis and the $q$-axis, respectively; $i_{d g}$ and $\mathrm{i}_{\mathrm{qg}}$ are the grid currents in the d-axis and the q-axis, respectively; wg represent the grid angular velocity.

\subsection{Significance of the control system}

The control objectives of the PMSG-wind turbine are considered constructed on governing the direct driven PMSG wind energy system, PMSG is directly fixed to the wind turbines to normalize the pitch angle of the blades which adjusts the swiftness and deliver protection to the system from any damage. The structure of the proposed controller is given in (Fig. 2). By consuming a full backto-back converter system, the supervisors for the GS and MSC, PMSG stator is associated to the utility grid. The SMC is the powerful non-linear controller, because of its efficiency, robustness, rapid dynamic response and high symmetry transaction switch control method for nonlinear provisions with uncertainties. SMC has been 
utilized for the PMSG pitch angle and torque, green energy arrangement is carried out deprived of the possibility that wind fleetness is measurable.

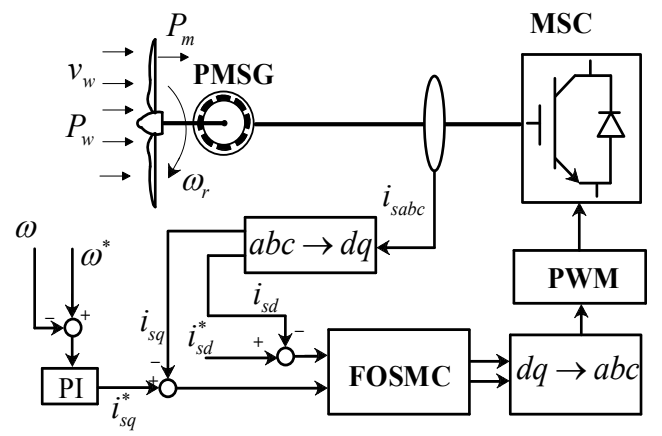

(a)

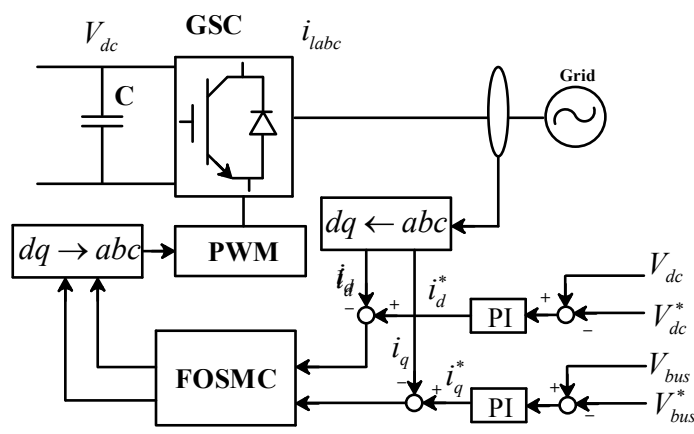

(b)

Fig. 2 Structure of the proposed FOSMC: (a) MSC; (b) GSC

One of the control missions of the PMSG based WECS is to generate the switching signal for the boost converter and the NPC inverter. The dynamic equations were used to control the effectiveness of the boost converter. The direct and quadrature grid current are tracked, which leads to the control of the voltage level/active and reactive power output. The regulating of the active power is carried out to change the angular swiftness of the wind-turbine rotor to follow characteristic of the rapidity of power of the turbine for pursuing the maximum power point. Secondly, the control mission is to adjust the active and reactive power injected to the grid, which can be eventually accomplished by the control of grid current direct and quadrature components. Thirdly, adjusting the voltage level, the DC-link capacitors were used in the NPC to control and provide the support for the grid voltage at the rotor side. Likewise, it can also be measured to produce/absorb reactive power for subsidiary the voltage at the grid side. Lastly, the reaching law adopted in the designing of the FOSMC preserves the ability of extenuating the chattering spectacle and also confirmations the strengths of the fastconvergent feature.

\section{Materials and Methods}

\subsection{Fractional order calculus}

Fractional Order calculus can be well-defined as; a symbol ${ }_{a} D_{t}^{\alpha}$ is the basic operator of fractional order calculus, where a and $t$ are the upper and lower limit of operators respectively. while, fractional order is represented by $\alpha$. Integral and difference order operators can be unified collected through the elementary procedure of the fractional calculus.

The integration of $\alpha$ - order function, $f(t): D_{t_{0}, t}^{\alpha} f(t)$ is:

$$
D_{t_{0}, t}^{\alpha} f(t)=\frac{1}{\Gamma(\alpha)} \int_{t_{0}}^{t}(t-\tau)^{\alpha-1} f(\tau) d \tau
$$

Where $f(t)$ is the function of time, $\alpha$ represents the fractional order, $\mathrm{t}$ and to are the final and primary intervals of period. While, gamma function is denoted by $\Gamma(\cdot)$.

Currently, significant research attention can be found in the field electrical and electronics engineering, pharmacy and medicines, bio-medical engineering, bio-chemistry and various other majors. Such as, robust and efficient controller design for wind turbines, an improved adaptive control technique for synchronization and designing of adaptive schemes by employing fractional order calculus. Hierarchical identification algorithm together with fractional order information filter is used to estimate and categorize the statuses and constraints of a fractional order structure (Pan et al., 2015;Ghasemi et al., 2014). In addition, the modeling of viscoelasticity along with biological tissues and cells have also been achieved completed by the exploitation of fractional order calculus (Psychalinos et al., 2016).

\subsection{Fractional order sliding mode control}

Owing to robustness point of view, fractional order SMC control technique is more beneficial because of its supplementary design constraints such as; regulating non-integer integrator/differentiator commands. In present research community, fractional order SMCs controllers have been established for renewable energy organizations, photovoltaic power generation systems, lighting control systems, and vector controlled sensor less induction motors (Zhang et al., 2014; Yin et al., 2014).

Consider the dynamic behavior of a system which is represented as:

$$
\dot{\Theta}=M(\Theta)+\tilde{M}(\Theta)+(N(\Theta)+\tilde{N}(\Theta)) U
$$

where, $\Theta=\left(\theta_{1}, \dot{\theta}_{1}, \cdots, \theta_{1}^{\left(r_{1}-1\right)}, \theta_{2}, \dot{\theta}_{2}, \cdots, \theta_{2}^{\left(r_{2}-1\right)}, \theta_{n}, \dot{\theta}_{2}, \cdots, \theta_{n}^{\left(r_{n}-1\right)}\right)^{T}$ represents the state vector, $\mathrm{M}(\Theta)$ and $\mathrm{N}(\Theta)$ are the vector functions of stator vector, $\tilde{M}(\Theta)$ and $\tilde{N}(\Theta)$ represent the uncertain factors of the vector functions, and $U$ denotes the control input of the system. Define the following fractional order sliding surface;

$$
S_{\text {switch }}=e+\Lambda D^{\alpha-1}\left(\operatorname{sig}(e)^{\gamma}\right)
$$

where

$$
e=\Theta-\Theta^{*}
$$

represent the tracking error vector, $\Lambda$ represents a diagonal matrix whose elements in the diagonal position are all positive, $\mathrm{D}^{\alpha-1}($.)is the $(\alpha-1)$ th order $\mathrm{R}$-L fractional order differential, and $\operatorname{sig}(\mathrm{e})^{\gamma}$ is defined as: 


$$
\operatorname{sig}(e)^{\gamma}=|e|^{\gamma} \operatorname{sgn}(e)
$$

Where $\operatorname{sgn}(e)$ represents the sign function and is denoted by

$$
\operatorname{sgn}(e)= \begin{cases}e /|e| & e \neq 0 \\ 0 & e=0\end{cases}
$$

Differentiating both sides of (7), we have;

$$
\dot{S}_{\text {switch }}=\dot{e}+\Lambda D^{1} D^{\alpha-1}\left(\operatorname{sig}(e)^{\gamma}\right)=\dot{e}+\Lambda^{C} D^{\alpha}\left(\operatorname{sig}(e)^{\gamma}\right)
$$

Generally, a reaching law is employed in order to guarantee the convergence and the reaching speed of the state vector trajectories from the initial point to the sliding surface. The reaching law is defined as:

$$
\dot{S}=S_{\text {law }}=F\left(S_{\text {switch }}\right)
$$

Then we obtain the control input of the dynamic system

$$
\begin{aligned}
& U=(N(\Theta)+\tilde{N}(\Theta))^{+}\left(F\left(S_{\text {switch }}\right)-M(\Theta)-\tilde{M}(\Theta)\right. \\
& \left.+\dot{\Theta}^{*}-\Lambda^{C} D^{\alpha-1}\left(\operatorname{sig}(e)^{\gamma}\right)\right)
\end{aligned}
$$

where $(N(\Theta)+\tilde{N}(\Theta))^{+}$represents the general inverse of the matrix $N(\Theta)+\tilde{N}(\Theta)$.

\subsection{FOSMC based wind turbine design}

One of the control missions of PMSG based WECS is to generate the switching signal for the boost converter and the NPC inverter. To control the boost converter, we need to consider the dynamic equation of (1)-(2). Hence, we take;

$$
e_{i}=I_{d c}-I_{d c}^{*}
$$

Where $I_{d c}{ }^{*}$ represents the reference value of $I_{d c}$. In Eq. (1) and Eq. (2), the only controllable variable is the duty cycle $q$. Based on the aforementioned FOSMC approach, the control input of the system is designed as:

$$
\begin{gathered}
q=\frac{R_{d c}}{V_{d c}} I_{d c}+\frac{V_{d c}-V_{r}}{V_{d c}}+\frac{d I_{d c}^{*}}{d t} \frac{L_{d c}}{V_{d c}}-\Lambda^{C} D^{\alpha_{1}}\left(\operatorname{sig}(e)^{\gamma}\right) \frac{L_{d c}}{V_{d c}} \\
-\frac{k_{1}}{\Pi\left(\varepsilon_{1}, N_{1}, S_{1}\right)} \operatorname{sign}\left(S_{1}\right) \frac{L_{d c}}{V_{d c}}
\end{gathered}
$$

where

$$
\Pi\left(\varepsilon_{1}, N_{1}, S_{1}\right)=\frac{1}{\left|S_{1}\right|+\varepsilon_{1}\left|S_{10}\right|}+\left(N_{1} k_{1}-\frac{1}{\left|S_{1}\right|+\varepsilon_{1}\left|S_{10}\right|}\right) e^{-\beta\left|S_{1}\right|^{p_{1}}}
$$

and

$$
S_{1}=e_{i}+\Lambda D^{\alpha_{1}-1}\left(\operatorname{sig}\left(e_{i}\right)^{\gamma}\right)
$$

$\varepsilon_{1}$ is a positive real number, $\left|\mathrm{S}_{10}\right|$ represents the initial value of the norm of the sliding surface, namely, $\left|\mathrm{S}_{1}\right|$ denotes a positive integer, $\mathrm{p} \geq 1$ is also a positive integer.

\subsection{FERL approach-based SMC}

To address the chattering spectacle without negotiating the accomplishment swiftness, the following FERL has been proposed:

$$
\dot{S}=\frac{k}{\Pi(\varepsilon, N, S)} \operatorname{sign}(S)
$$

Now considering the submission of the FERL approach in nonlinear schemes. Take in account the subsequent nonlinear system:

$$
\left(\begin{array}{c}
\dot{x}_{1} \\
\dot{x}_{2}
\end{array}\right)=\left(\begin{array}{c}
x_{2} \\
x_{1}^{2}+x_{2}^{2}
\end{array}\right)+\left(\begin{array}{c}
0 \\
2 x_{1}^{2}+x_{2}^{2}
\end{array}\right) u
$$

Where $u$ and $x$ are the control and state vector, respectively. It can be moved to the second order nonlinear scheme taking the below equation:

$$
\ddot{x}=x^{2}+\dot{x}^{2}+\left(2 x^{2}+\dot{x}^{2}\right) u,
$$

where $x=x_{1}, x_{2}=\dot{x}_{1}$. The surface of the switching is

$S=\chi x+\dot{x}$

where $\chi_{\text {represent a positive real number, therefore, we }}$ have

$\ddot{x}=\dot{S}-\chi \dot{x}$,

by substituting the FERL reaching law Eq. (18) into Eq. (22), we have

$\ddot{x}=\frac{k}{\Pi(\varepsilon, N, S)} \operatorname{sign}(S)-\chi \dot{x}$,

now substituting Eq. (23) into Eq. (20), the control input can be attained as

$$
u=\frac{1}{2 x^{2}+\dot{x}^{2}}\left(-\frac{k}{\Pi(\varepsilon, N, S)} \operatorname{sign}(S)-\chi \dot{x}-x^{2}-\dot{x}^{2}\right) .
$$

The reaching law adopted in the designing of the FOSMC possesses the capability of mitigating the chattering phenomenon and also shows the strengths of fast convergent feature, as shown in (Fig. 3). It can be figured out, that the FERL based FOSMC can approach the equilibrium point more directly. Meanwhile, the enlarged image indicates that there are merely any 
chatters in the trajectory of the FERL based FOSM when the chatters of other trajectories are apparently high. It is worth mentioning that the MPPT algorithm is adopted to obtain the desired current $\mathrm{L}_{\mathrm{dc}}$.

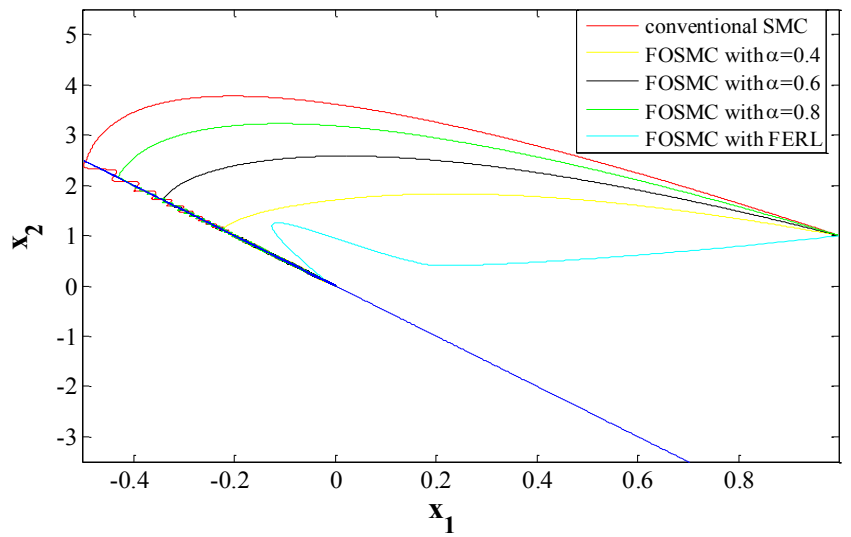

(a)

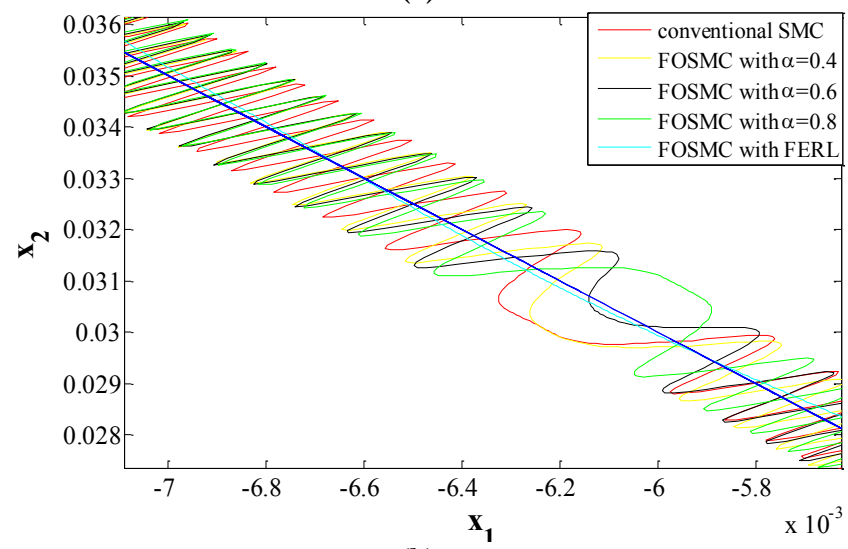

(b)

Fig. 3 The reaching trajectories of the conventional SMC, FOSMC and the FERL based FOSMC: (a) The original images; (b) The partially enlarged images

Now control of the boost converter is accomplished, the remained problem is to control the NPC inverter expressed by Eq's. (3)-(4). In the two equations, the controllable variables are $v_{\text {di }}$ and $v_{\text {qii }}$. The control mission is to regulate the active and reactive power injected to the grid, which can be ultimately accomplished by the control of grid current direct and quadrature components. Following the same procedure of the designing of the boost converter control, the control signals of $v_{\text {di }}$ and $v_{\text {qi }}$ are designed as:

$$
\begin{aligned}
& v_{d i}=\frac{d i_{d g}^{*}}{d t} L_{f}-\Lambda^{C} D^{\alpha_{2}}\left(\operatorname{sig}\left(e_{d}\right)^{\gamma}\right) L_{f}+R_{f} i_{d g}+v_{d g} \\
& -w_{g} i_{q g} L_{f}-\frac{k_{2}}{\Pi\left(\varepsilon_{2}, N_{2}, S_{2}\right)} \operatorname{sign}\left(S_{2}\right) L_{f}
\end{aligned}
$$

and

$$
\begin{aligned}
& v_{q i}=\frac{d i_{q g}^{*}}{d t} L_{f}-\Lambda^{C} D^{\alpha_{3}}\left(\operatorname{sig}\left(e_{q}\right)^{\gamma}\right) L_{f}+R_{f} i_{q g}+v_{q g} \\
& +w_{g} i_{d g} L_{f}-\frac{k_{3}}{\Pi\left(\varepsilon_{3}, N_{3}, S_{3}\right)} \operatorname{sign}\left(S_{3}\right) L_{f}
\end{aligned}
$$

where $e_{d}=i_{d g}-i_{d g}^{*}, \quad e_{q}=i_{q g}-i_{q g}^{*}$, and the remained parameters have the same meanings as those of Eq. (13), which are neglected for purpose of simplicity.

\subsection{Stability analysis of the system}

The stability study for any system is very crucial for originating the arrangement necessities that assurance the constancy of the entire system and impose the state routes to the symmetry manifold. The most commonly approach used for the system stability analysis is Lyapunov function approach. therefore, we choose the subsequent Lyapunov entrant function:

$V(t)=\frac{1}{2} S^{T} S$

which usually stay semi-positive throughout the entire period. Thus, the time derivative of $\mathrm{V}(\mathrm{t})$ is

$\dot{V}(t)=S^{T} \dot{S}=S^{T} \frac{k}{\Pi(\varepsilon, N, S)} \operatorname{sign}(S)$.

By substituting the control approach into Eq. (28), we get,

$$
\begin{aligned}
& \dot{V}(t)=-\left(\frac{k_{P} S_{P}\left|S_{P}\right|^{r_{P}} \operatorname{sign}\left(S_{P}\right)}{\Pi\left(\varepsilon_{p}, N_{p}, S_{p}\right)}+\frac{k_{Q} S_{Q}\left|S_{Q}\right|^{r_{Q}} \operatorname{sign}\left(S_{Q}\right)}{\Pi\left(\varepsilon_{Q}, N_{Q}, S_{Q}\right)}\right) \\
& \leq \frac{\left(k_{P}\left|S_{P}\right|^{2}+k_{Q}\left|S_{Q}\right|^{2}\right)}{\Pi_{\max }} \\
& \leq \frac{k_{\min }\left(\left|S_{P}\right|^{2}+k_{Q}\left|S_{Q}\right|^{2}\right)}{\Pi_{\max }} \\
& =-\frac{k_{\min }}{\Pi_{\max }} \mid S \|_{2}^{2}<0
\end{aligned}
$$

where $\Pi_{\max }=\max \left\{\Pi_{P}, \Pi_{Q}\right\}, k_{\min }=\min \left\{k_{P}, k_{Q}\right\} \cdot$ Hence, $\quad \dot{V}(t)$ approached negative and will be negative without additional constraints in the controller parameters. Thus, the asymptotic convergence can be guaranteed for the system state variables.

\section{Results and Discussion}

The simulation is conducted in MATLAB/Simulink to verify the effectiveness and evaluate the performance of the proposed FOSMC in PMSG wind turbine application. The parameter settings involved are listed in (Table 1).

The power coefficient corresponding to the tip speed ratio is shown in (Fig. 4). At a value of 1.4 the power coefficient starts rising and reach to maximum value of 0.25 at a tip speed ratio of 9 , while it touches the zero point again at a tip speed ratio of 16 . Similarly, in real time operation of PMSG-wind turbine, the stability factor of variable wind flow plays a key role. Thus, to extract a maximum power from the wind to the grid station and sustain output power as reliable as possible. A variable wind speed cure is shown in (Fig. 5). It is clear from the graph that the average wind speed is near to $10 \mathrm{~m} / \mathrm{s}$ for 
Citation: Khan, M.W., Wang, J., Xiong, L. and Ma, M. (2019). Fractional Order Sliding Mode Control of PMSG-Wind Turbine Exploiting Clean Energy Resource. Int. Journal of Renewable Energy Development, 8(1), 81-89, doi.org/10.14710/ijred.8.1.81-89

$\mathrm{P}$ a g e $\mid 86$

the system. With the pre-calculated optimum value of tip speed ratio value and power coefficient, we are able to capture the maximum wind energy. The aforementioned switch function is shown in (Fig. 6).

Table 1

FOSM based WECS parameters

\begin{tabular}{ll}
\hline Parameters & Value \\
\hline Nominal power & $8 \mathrm{~kW}$ \\
Nominal stator frequency & $50 \mathrm{~Hz}$ \\
Magnetizing inductance, $L_{m}$ & $2.7 \mathrm{mH}$ \\
Stator leakage inductance, $L_{\sigma s}$ & $59.921 \mu \mathrm{H}$ \\
Rotor leakage inductance, $L_{\sigma r}$ & $82.060 \mu \mathrm{H}$ \\
DC-link nominal voltage, $V_{d c}$ & $1200 \mathrm{~V}$ \\
Fractional order $\alpha_{1}$ & 0.4 \\
Fractional order $\alpha_{2}$ & 0.6 \\
Fractional order $\alpha_{3}$ & 0.8 \\
\hline
\end{tabular}

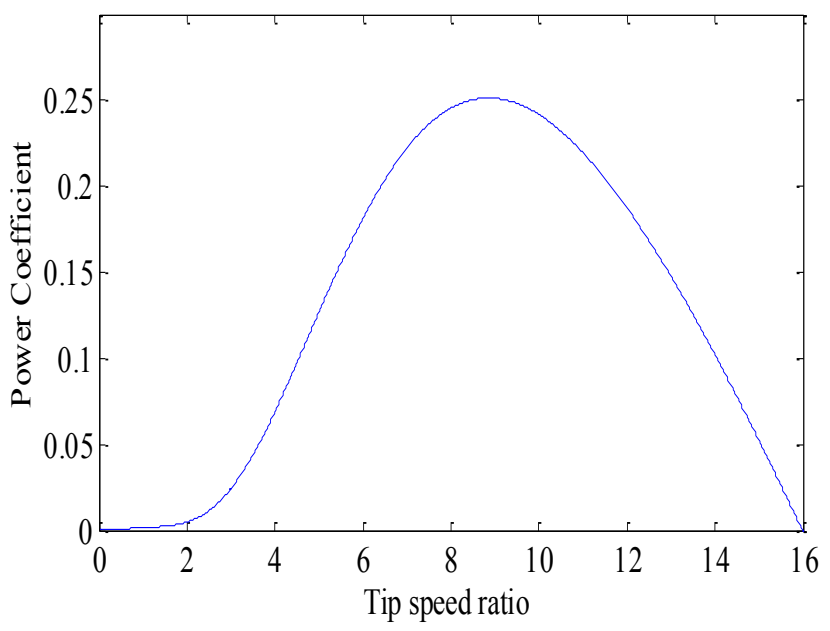

Fig. 4 Power coefficient corresponding to the tip speed ratio

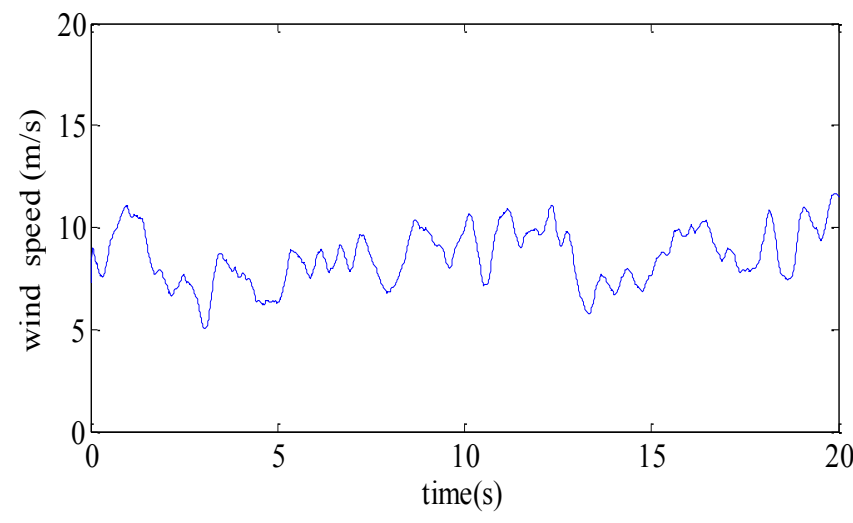

Fig. 5 Variable wind speed curve

As shown in the (Fig. 7(a,b)), the tracking value of the direct and quadrature axis current are more symmetrical to that of the referenced value. Hence, the FOSMC based wind energy conversion approach can accurately achieve the referenced value for better procedures to extract the precise power output, which leads to the control of the active and reactive power output.
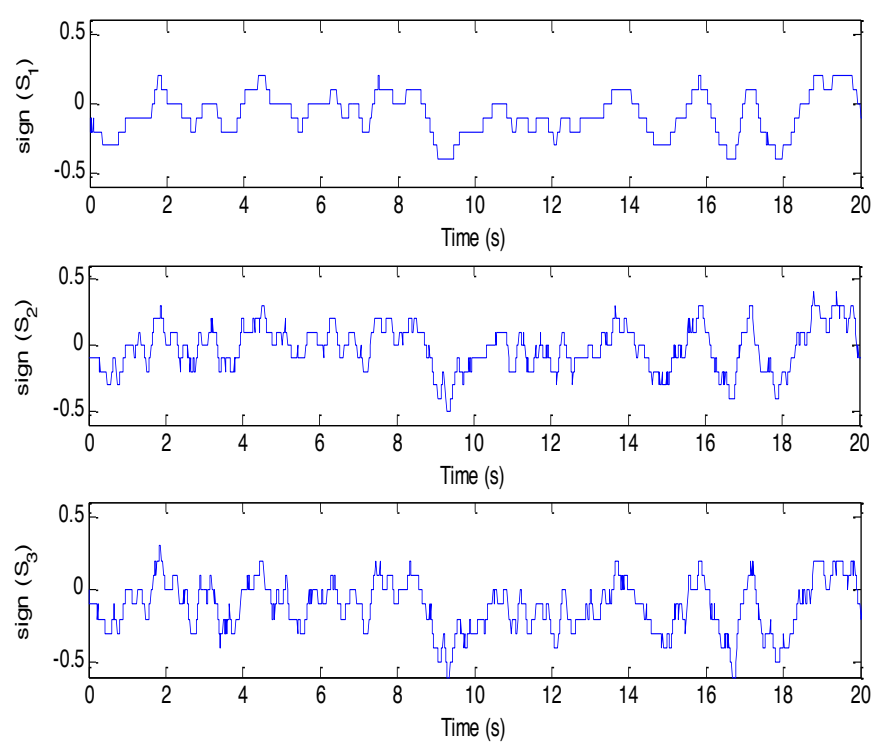

Fig. 6 Switching functions for seizing maximum wind energy

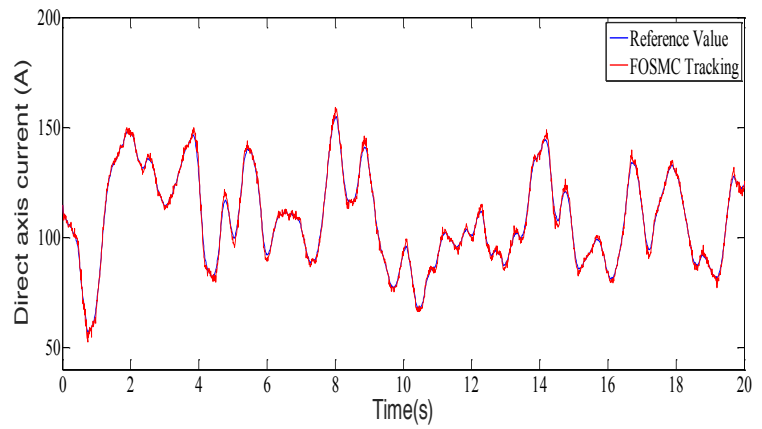

(a)

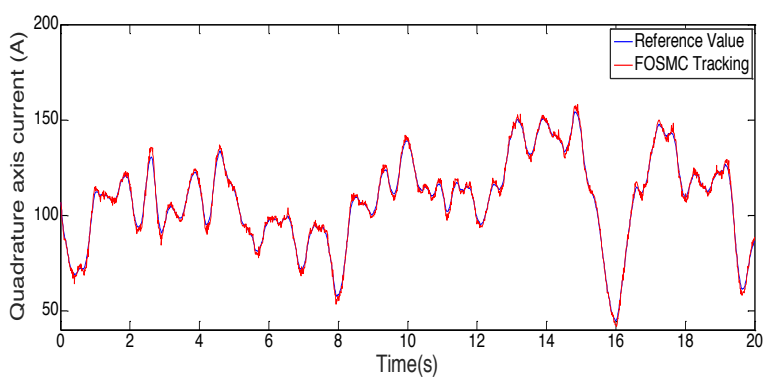

(b)

Fig. 7 Output curves of the controller with referenced value: (a) Direct axis current; (b) Quadrature axis current

The wind power extraction procedure is shown in (Fig. 8). It can be seen, that with the FOSMC approach, the actual active power and reactive power can track the reference value in a precise and stable manner. Adopting the conventional SMC approach, however, high frequency chatters exist in the tracking curves. The dc-link voltages with FOSMC and the conventional SMC is shown in (Fig. 
9). By comparing both the dc-link voltages of conventional SMC and FOSMC, it is notable that the FOSMC has smooth curves and almost stable throughout the scheduled time while the conventional SMC has more variations especially by considering the Vdc1.

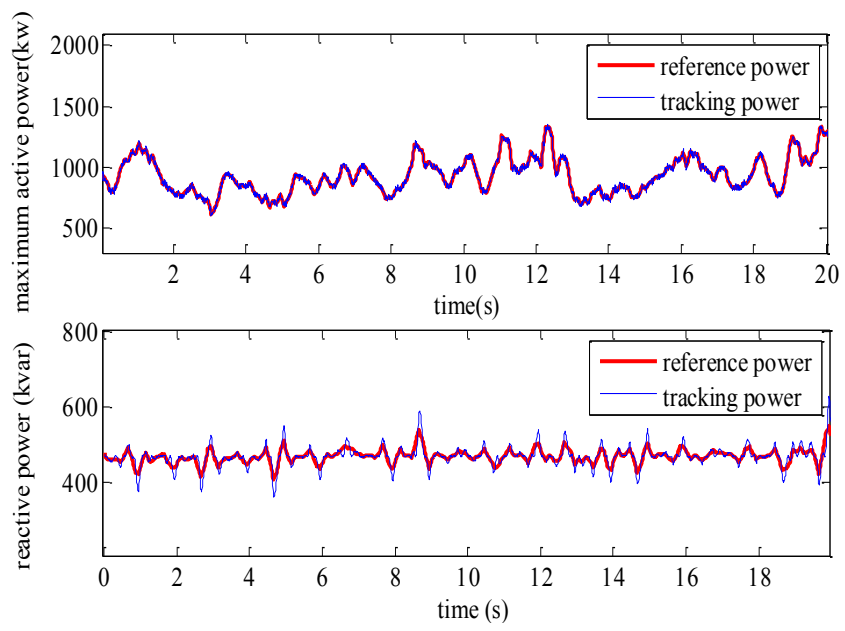

(a)

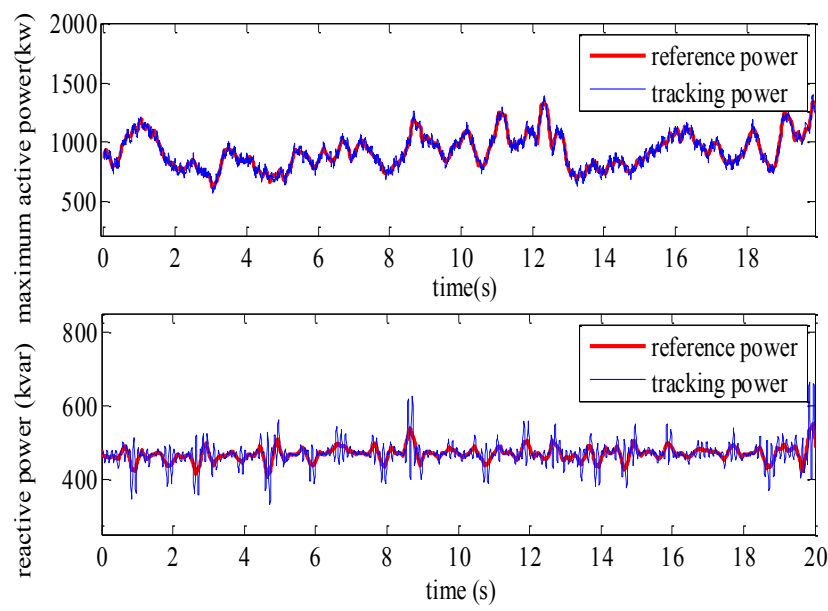

(b)

Fig. 8 Wind power extraction with the FOSMC and the conventional SMC: (a) FOSMC based wind power extraction; (b) Conventional SMC tracking

\subsection{Performance evaluation of the FOSMC}

In order to track and assess the performance of both the approaches in a measurable way, the integral square error (ISE) is followed, which is well-defined as (Ling et al., 2011),

$$
I S E=\int_{0}^{\infty}[e(t)]^{2} d t
$$

where e(t) signifies the error in the system among the actual and the referenced value. The standardized ISE indices of the reactive and active power tracking curves of the conventional SMC approach are 87.7365 and 19.5201, respectively; and the proposed FERL-based FOSMC technique are 7.6838 and 2.3879, respectively.
By comparing the performance evaluations of both the systems, it is clearly shown that the tracking error of the proposed FOSMC technique is much lower than that of the SMC stating to the ISE indices of both the reactive and active power tracking.

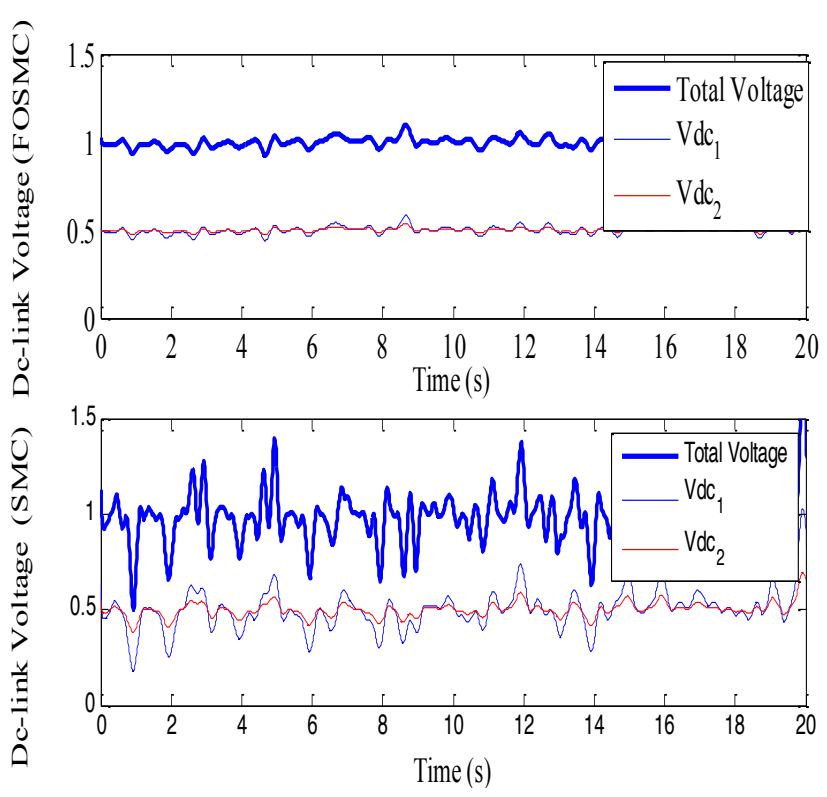

Fig. 9 DC-link voltages with FOSMC and the conventional SMC

The ISE performance indices of the proposed and the conventional approaches in different time intervals are deliberated in (Fig. 10). These performance indices are envisioned after every $0.5 \mathrm{~s}$ for the sake to approve the tracking tendency. Noticeably, the conventional SMC has much higher ISE indices than the FERL-based FOSMC technique and therefore the ISE performance indices of the proposed controller are stable in the whole time period.

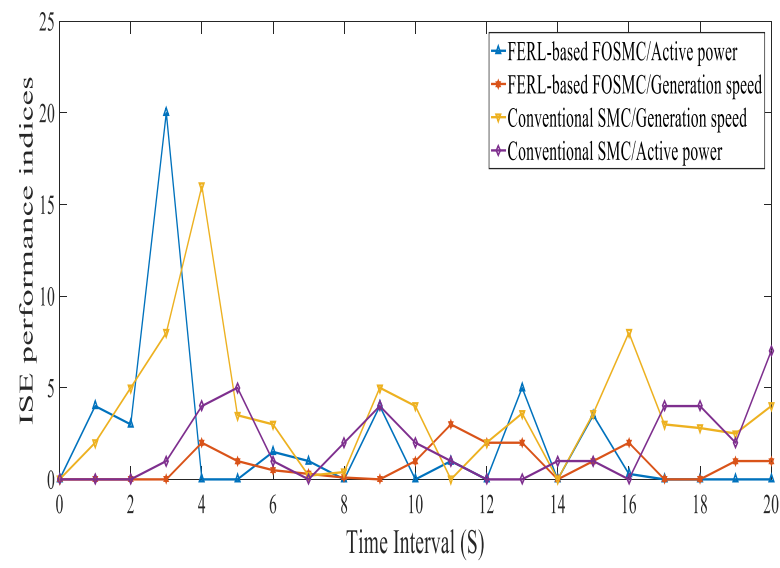

Fig. 10 ISE performance evaluation of the proposed FOSMC and conventional SMC

Secondly, to further evaluate the performance of the proposed controller the voltage and current at the PCC with the conventional SMC approach and the proposed FOSMC approach are shown in (Fig. 11). The total harmonic distortion in the proposed method is nearly $2 \%$ which is resolved for about $98 \%$ while almost $5 \%$ in the 
conventional SMC approach. It can be figured out, that with the conventional SMC approach, there are high frequency chatters in the current component. For the FOSMC approach, however, the chatters merely exist. Hence, the superior performance of the proposed FOSMC can be witnessed.
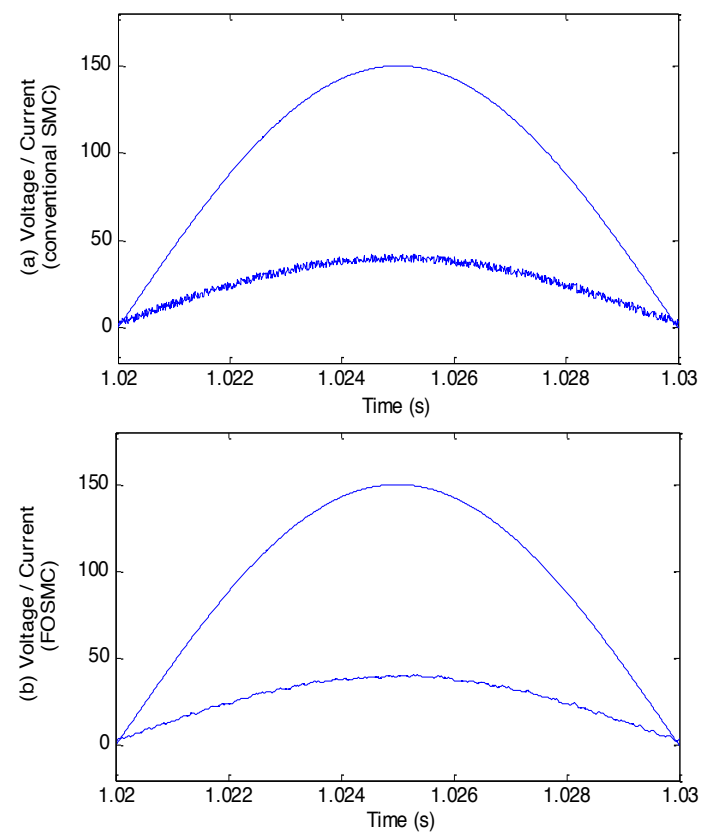

Fig. 11 Voltage and current at the PCC with the conventional SMC approach and the proposed FOSMC approach

\section{Conclusion}

This paper proposed a FOSM-based power output control of PMSG based WECS with FERL. The concept of fractional order calculus is integrated with the theory of SMC and the sliding surface is constructed with fractional order derivatives. The integration of FERL with the FOSM largely mitigates the chattering level of the state vector trajectories and accelerates the approaching process. In designing the controller of the PMSG based WECS, the boost converter and the NPC inverter are controlled to realize the output active and reactive power control. The simulation results verified the effectiveness and superior performance of the proposed method.

\section{List of abbreviations}

PMSG

Permanent magnet synchronous generator

FOSMC

FERL

WECS

FOSM

PCC

MPPT

MSC

GSC

SMC

$\mathrm{AC}$
DC

NPC

ISE

\section{Acknowledgments}

The authors wish to thank the respected editors and reviewers for their pertinent and constructive comments and acknowledge support received from the National Natural Science Foundation of China under Grant no. 61374155, and the Specialized Research Fund for the Doctoral Program of Higher Education P R China under Grant no. 20130073110030.

\section{References}

Delfino, F., Pampararo, F., Procopio, R., \& Rossi, M. (2012). A feedback linearization control scheme for the integration of wind energy conversion systems into distribution grids. IEEE systems journal, 6(1), 85-93.

Fatu, M., Blaabjerg, F., \& Boldea, I. (2014). Grid to standalone transition motion-sensorless dual-inverter control of PMSG with asymmetrical grid voltage sags and harmonics filtering. IEEE Transactions on Power Electronics, 29(7), 3463-3472.

Ghasemi, S., Tabesh, A., \& Askari-Marnani, J. (2014). Application of fractional calculus theory to robust controller design for wind turbine generators. IEEE transactions on energy conversion, 29(3), 780-787.

Hui, J. C., Bakhshai, A., \& Jain, P. K. (2016). An energy management scheme with power limit capability and an adaptive maximum power point tracking for small standalone PMSG wind energy systems. IEEE Transactions on Power Electronics, 31(7), 4861-4875.

Khan, M. W., Wang, J., Xiong, L., \& Ma, M. (2018). Modelling and optimal management of distributed microgrid using multi-agent systems. Sustainable Cities and Society, 41, 154-169.

Lee, S. H., Joo, Y. J., Back, J. H., Seo, J. H., \& Choy, I. (2011). Sliding mode controller for torque and pitch control of PMSG wind power systems. Journal of Power Electronics, 11(3), 342-349.

Li, S., Haskew, T. A., Swatloski, R. P., \& Gathings, W. (2012). Optimal and direct-current vector control of direct-driven PMSG wind turbines. IEEE Transactions on power electronics, 27(5), 2325-2337.

Ling, K. V., Ho, W. K., Feng, Y., \& Wu, B. F. (2011). Integralsquare-error performance of multiplexed model predictive control. IEEE transactions on industrial informatics, $7(2)$, 196-203.

Melício, R., Mendes, V. M. F., \& Catalão, J. P. D. S. (2010). Fractional-order control and simulation of wind energy systems with PMSG/full-power converter topology. Energy Conversion and Management, 51(6), 1250-1258.

Mozayan, S. M., Saad, M., Vahedi, H., Fortin-Blanchette, H., \& Soltani, M. (2016). Sliding mode control of PMSG wind turbine based on enhanced exponential reaching law. IEEE Transactions on Industrial Electronics, 63(10), 6148-6159.

Muyeen, S. M., \& Al-Durra, A. (2013). Modeling and control strategies of fuzzy logic controlled inverter system for grid interconnected variable speed wind generator. IEEE systems journal, 7(4), 817-824.

Nascimento, E. M., \& de Souza, J. D. (2017). Hybrid Power Plants: Viability for Cities in Minas Gerais. Engineering Journal, 21(5), 37-52.

Nguyen, T. H., \& Lee, D. C. (2013). Advanced fault ride-through technique for PMSG wind turbine systems using line-side converter as STATCOM. IEEE transactions on industrial electronics, $60(7), 2842-2850$. 
Pan, I., \& Das, S. (2015). Kriging based surrogate modeling for fractional order control of microgrids. IEEE Transactions on Smart grid, 6(1), 36-44.

Pradhan, R., Majhi, S. K., Pradhan, J. K., \& Pati, B. B. (2017). Performance Evaluation of PID Controller for an Automobile Cruise Control System using Ant Lion Optimizer. Engineering Journal, 21(5), 347-361.

Psychalinos, C., Elwakil, A. S., Radwan, A. G., \& Biswas, K. (2016). Guest editorial: fractional-order circuits and systems: theory, design, and applications. Circuits, Systems, and Signal Processing, 35(6), 1807-1813.

Santiprapan, P., Areerak, K., \& Areerak, K. (2017). The Implementation of Active Power Filter using Proportional plus Resonant Controller. Engineering Journal, 21(6), 6980.

Yin, C., Chen, Y., \& Zhong, S. M. (2014). Fractional-order sliding mode based extremum seeking control of a class of nonlinear systems. Automatica, 50(12), 3173-3181.

Yin, X. X., Lin, Y. G., Li, W., Liu, H. W., \& Gu, Y. J. (2015). Fuzzy-logic sliding-mode control strategy for extracting maximum wind power. IEEE Transactions on Energy Conversion, 30(4), 1267-1278.

Yuan, X., Wang, F., Boroyevich, D., Li, Y., \& Burgos, R. (2009). DC-link voltage control of a full power converter for wind generator operating in weak-grid systems. IEEE Transactions on Power Electronics, 24(9), 2178-2192.

Zhang, Z., Zhao, Y., Qiao, W., \& Qu, L. (2014). A space-vectormodulated sensorless direct-torque control for direct-drive PMSG wind turbines. IEEE Transactions on Industry Applications, 50(4), 2331-2341.

Zhong, Q. C., Ma, Z., Ming, W. L., \& Konstantopoulos, G. C. (2015). Grid-friendly wind power systems based on the synchronverter technology. Energy Conversion and Management, 89, 719-726.

Zhou, D., Blaabjerg, F., Franke, T., Tønnes, M., \& Lau, M. (2015). Comparison of wind power converter reliability with low-speed and medium-speed permanent-magnet synchronous generators. IEEE Transactions on Industrial Electronics, 62(10), 6575-6584. 